\title{
The efficacy of sevolflurane inhalation alone or its combination with intravenous remifentanil against withdrawal movements on rocuronium injection in children
}

\author{
Yun Chan Na, Hyung Gon Lee, Seong Heon Lee, Eun A Jang, and Myung Ha Yoon \\ Department of Anesthesiology and Pain Medicine, Chonnam National University, Medical School, Gwangju, Korea
}

Background: The aims of this study were to compare the efficacy of sevoflurane inhalation alone, intravenous remifentanil alone, and the combination of sevoflurane inhalation and remifentanil as pretreatment for the prevention of rocuronium-induced withdrawal movement in pediatric patients.

Methods: In this prospective, randomized study, 90 American Society of Anesthesiologists physical status I or II pediatric patients aged 3 to 10 years were randomly allocated to one of three treatment groups: The Group $\mathrm{S}$ comprising the patients receiving sevoflurane inhalation, the Group R comprising those doing intravenous remifentanil $0.5 \mu \mathrm{g} / \mathrm{kg}$ and the Group C comprising those doing sevoflurane inhalation+intravenous remifentanil $0.5 \mu \mathrm{g} / \mathrm{kg}$. The response of the patients was graded based on a 4-point scale.

Results: The overall incidence of withdrawal movement on rocuronium injection was 54\% (16/30) in the Group S, 57\% (17/30) in the Group R and 17\% (5/30) in the Group C. There was no significant difference in the incidence of withdrawal movements on rocuronium injection between the Group S and Group R. In addition, the incidence of withdrawal movements and generalized movement on rocuronium injection was significantly lower in the Group $\mathrm{C}$ as compared with the Group $S$ and $R(P<0.05)$.

Conclusions: Our results indicate not only that there was no significant difference in the degree of the effect in lowering the incidence of withdrawal movements on rocuronium injection between sevoflurane inhalation and intravenous remifentanil but also that it was significantly higher when combined with intravenous remifentanil as compared with the single use of sevoflurane inhalation or intravenous remifentanil. (Korean J Anesthesiol 2014; 67: 373-377)

Key Words: Injections, Pain, Pediatrics, Remifentanil, Rocuronium, Sevoflurane.

\footnotetext{
Received: April 30, 2014. Revised: 1st, June 17, 2014; 2nd, July 2, 2014. Accepted: July 8, 2014.

Corresponding author: Myung Ha Yoon, M.D., Ph.D., Department of Anesthesiology and Pain Medicine, Chonnam National University, Medical School, 42, Jebong-ro, Dong-gu, Gwangju 501-757, Korea. Tel: 82-62-220-6895, Fax: 82-62-232-6294, E-mail: mhyoon@chonnam.ac.kr This is a thesis for a Master's degree.

(c) This is an open-access article distributed under the terms of the Creative Commons Attribution Non-Commercial License (http:// creativecommons.org/licenses/by-nc/3.0/), which permits unrestricted non-commercial use, distribution, and reproduction in any medium, provided the original work is properly cited.
} 


\section{Introduction}

Rocuronium is an aminosteroidal non-depolarizing muscle relaxant, and it is characterized by a rapid onset of action of intermediate duration. In addition, it is frequently used to promote the tracheal intubation during the induction of general anesthesia. An intense burning sensation, pain on rocuronium injection is a common side effect that has been reported to occur in 50$100 \%$ of awake patients [1]. Moreover, withdrawal movements, such as withdrawal of the injected hand and arm or generalized body movement, occur as a result of intravenous rocuronium even after loss of consciousness during induction of anesthesia. Presumably, this might be due to injection pain [1]. Such withdrawal movements may also cause injury and displacement of intravenous catheters, thus making it difficult to administer additional drugs and subsequently increasing patients at risks of developing cardiovascular adverse effects.

Pediatric patients are at greater risks of developing withdrawal movements; they have been reported to occur at an incidence of $83-94 \%$ [2,3]. In extreme cases, there may be detrimental outcomes. That is, the pulmonary aspiration may also occur as a result of gastric regurgitation in these cases [4]. Moreover, it would be mandatory to prevent the occurrence of withdrawal movements in children. This is because they may present with fatal complications arising from the re-cannulation of tiny vessels through the extensive subcutaneous fat when there is a lack of the intravenous access.

Numerous strategies have been proposed to decrease the pain on rocuronium injection in children, whose successful results have been reported to vary. They include slow injection [5] as well as pre-treatment with ketamine [2], lidocaine [6] and opioids [7].

Sevoflurane is an inhalation agent that is commonly used in children. Its preventive effects against withdrawal movements on rocuronium injection during the induction of inhalation anesthesia have recently been well documented [8]. In addition, there are also several reports about the preventive effects of opioids against withdrawal movements on rocuronium injection, whose results have been reported to vary in children [3,7,9]. As compared with other opioids, remifentanil is advatageous in shortening the time of induction anesthesia because of faster onset and shorter duration [10].

Given the above background, we conducted this study not only to compare the efficacy of sevoflurane inhalation with that of intravenous remifentanil in preventing the occurrence of withdrawal movements on rocuronium injection but also to examine whether there is an increase in the degree of the effect of sevoflurane inhalation against withdrwal movements on rocuronium injection when combined with intravenous remifentanil as compared with the single use of sevoflurane inhalation or intravenous remifentanil.

\section{Materials and Methods}

The current study was approved by the Institutional Review Board of our medical institution. We obtained a written informed consent from the parents of all the patients. We prospectively evaluated a total of 90 children aged between three and ten years, with the American Society of Anesthesiologists physical status I or II, undergoing general anesthesia for elective ophthalmic surgery.

Exclusion criteria for the current study are as follows:

(1) The patients with known opioid allergies

(2) The patients with asthma

(3) The patients with neurologic deficits

(4) The patients with a history of taking analgesics or sedatives within the previous $24 \mathrm{~h}$

(5) The patients who were crying upon arrival at the operating room.

Using a computer-generated randomized table in a sealed envelope, we randomly assigned the patients to one of the following three groups:

(1) The Group $S(n=30)$ : The patients receiving sevoflurane inhalation

(2) The Group $\mathrm{R}(\mathrm{n}=30)$ : The patients receiving intravenous remifentanil $0.5 \mu \mathrm{g} / \mathrm{kg}$

(3) The Group C $(n=30)$ : The patients receiving sevoflurane inhalation + intravenous remifentanil $0.5 \mu \mathrm{g} / \mathrm{kg}$

Patients, anesthesia providers, and investigators who scored the movements were blinded to the treatment group. An independent researcher prepared the study solutions: a $10 \mathrm{ml}$ of the mixture of remifentanil $0.5 \mu \mathrm{g} / \mathrm{kg}$ and normal saline for the Group R and Group C and a $10 \mathrm{ml}$ of normal saline for the Group S.

The patients were not pre-medicated prior to surgery. Prior to arrival at an operation room, the patients underwent insertion of a 24-gauge cannula in the dorsum of the hand. This was confirmed based on the gravity of a free flow of dextrose/saline infusion. All the patients were monitored for electrocardiography, pulse oximetry, non-invasive blood pressure, capnography and end-tidal sevoflurane concentration at an operation room. All the drugs were administered through the rubber port connected to the intravenous cannula with a free flow of intravenous fluid. Anesthesia was induced with $2.5 \%$ thiopental sodium at a dose of $5 \mathrm{mg} / \mathrm{kg}$. After the loss of consciousness was confirmed by abolition of the eyelash reflex, the patients received injections of remifentanil or saline for more than 30 seconds. Mask ventilation was initiated with $100 \%$ oxygen once the patient became unconscious and apneic. Sevoflurane was started after thiopental injection, whose end-tidal concentration was adjusted at $2 \mathrm{vol} \%$ in $100 \%$ oxygen in the Group S and Group C. In the Group R, sevoflurane was started after rocuronium injection, whose end- 
tidal concentration was adjusted at 2 vol\% in $100 \%$ oxygen. Two minutes thereafter, rocuronium $1 \%(0.6 \mathrm{mg} / \mathrm{kg})$ was injected for more than ten seconds. The response of the patients was graded as proposed by Shevchenko et al. [11]: $1=$ no response, $2=$ movement at the wrist only, $3=$ movement/withdrawal involving the arm only (elbow/shoulder) and $4=$ generalized response, movement/withdrawal in more than one extremity. The trachea was intubated two minutes after the rocuronium injection, which was followed by the mechanical ventilation of the lung. Thus, attempts were made to maintain normocarbia. Anesthesia was maintained with sevoflurane at an end-tidal concentration of $2-4 \mathrm{vol} \%$ in oxygen/nitrous oxide $\left(\mathrm{FIO}_{2}=0.5\right)$. The mean arterial pressure (MAP) and heart rate (HR) were recorded upon arrival at an operation room, served as baseline value, and before and one minute after tracheal intubation.

Based on previous studies $[2,3]$, we estimated the incidence of withdrawal movements on rocuronium injection in children at $90 \%$. Then, assuming a reduction of $40 \%$ at a $5 \%$ level of significance and $90 \%$ test power, we considered that we required at least 30 patients per group for the current study.

\section{Statistical analysis}

Statistical analysis was done using the SPSS software version 15.0 for windows (SPSS, Inc., Chicago, IL, USA). We also used the analysis of variance (ANOVA) to compare demographic data, served as the continuous variables, such as the age, height

Table 1. Demographic Data

\begin{tabular}{lccc}
\hline & $\begin{array}{c}\text { Group S } \\
(\mathrm{n}=30)\end{array}$ & $\begin{array}{c}\text { Group R } \\
(\mathrm{n}=30)\end{array}$ & $\begin{array}{c}\text { Group C } \\
(\mathrm{n}=30)\end{array}$ \\
\hline Sex $(\mathrm{M} / \mathrm{F})$ & $13 / 17$ & $14 / 16$ & $14 / 16$ \\
Age $(\mathrm{yr})$ & $6.8 \pm 1.7$ & $7.2 \pm 1.9$ & $6.8 \pm 1.4$ \\
Weight $(\mathrm{kg})$ & $25.8 \pm 10.4$ & $26.6 \pm 9.1$ & $25.9 \pm 6.1$ \\
Height $(\mathrm{cm})$ & $121 \pm 10$ & $123 \pm 11$ & $122 \pm 9$ \\
\hline
\end{tabular}

Values are shown as means \pm SD or numbers of patient. There were no significant differences among the groups. Group S: Sevoflurane group, Group R: Remifentanil group, Group C: Sevoflurane and remifentanil combination group. and weight, and $\chi^{2}$-test to do discrete variables ones, such as sex, between the three groups. In addition, we used the Fisher's exact test to compare the incidence withdrawal movements on rocuronium injection between the three groups. Furthermore, we analyzed time-dependent changes in the hemodynamic variables using the repeated-measures ANOVA in each group and compared them using the one-way ANOVA between the three groups. A P value of $<0.05$ was considered statistically significant.

\section{Results}

As shown in Table 1, there were no significant differences in demographic characteristics between the three groups.

The overall incidence of withdrawal movement on rocuronium injection was 54\% (16/30) in the Group S, 57\% (17/30) in the Group R and 17\% (5/30) in the Group C. In addition, the incidence of generalized movement (grade 4$)$ was $20 \%(6 / 30)$, $17 \%(5 / 30)$ and $0 \%(0 / 30)$ in the corresponding order.

As shown in Table 2, there was no significant difference in the incidence of withdrawal movements on rocuronium injection between the Group S and Group R. In addition, the incidence of withdrawal movements and generalized movement on rocuronium injection was significantly lower in the Group $\mathrm{C}$ as compared with the Group $\mathrm{S}$ and $\mathrm{R}(\mathrm{P}<0.05)$.

As shown in Table 3, MAP and HR were significantly increased in all the three groups after tracheal intubation as com-

Table 2. Incidence and Grade of Withdrawal Movements Associated with Rocuronium Injection

\begin{tabular}{lrrc}
\hline $\begin{array}{c}\text { Grade of withdrawal } \\
\text { movements }\end{array}$ & $\begin{array}{c}\text { Group S } \\
(\mathrm{n}=30)\end{array}$ & $\begin{array}{c}\text { Group R } \\
(\mathrm{n}=30)\end{array}$ & $\begin{array}{c}\text { Group C } \\
(\mathrm{n}=30)\end{array}$ \\
\hline 1 (no withdrawal) & $14(46)$ & $13(43)$ & $25(83)^{*}$ \\
2 (wrist withdrawal) & $5(17)$ & $3(10)$ & $5(17)$ \\
3 (arm only) & $5(17)$ & $9(30)$ & $0(0)^{*}$ \\
4 (generalized movement) & $6(20)$ & $5(17)$ & $0(0)^{*}$ \\
\hline
\end{tabular}

Data are given as numbers of patients (\%). Group S: Sevoflurane group, Group R: Remifentanil group, Group C: Sevoflurane and remifentanil combination group. ${ }^{*} \mathrm{P}<0.05$ compared with Group $\mathrm{S}$ and Group $\mathrm{R}$.

Table 3. Mean Arterial Pressure and Heart Rate during Anesthetic Induction

\begin{tabular}{|c|c|c|c|c|c|c|}
\hline & \multicolumn{3}{|c|}{ MAP } & \multicolumn{3}{|c|}{ HR } \\
\hline & Baseline & $\begin{array}{c}\text { Before } \\
\text { intubation }\end{array}$ & $\begin{array}{l}1 \text { min after } \\
\text { intubation }\end{array}$ & Baseline & $\begin{array}{c}\text { Before } \\
\text { intubation }\end{array}$ & $\begin{array}{l}1 \text { min after } \\
\text { intubation }\end{array}$ \\
\hline Group S & $85.0 \pm 11.3$ & $75.9 \pm 11.9^{*}$ & $99.8 \pm 15.2^{*}$ & $95.8 \pm 16.6$ & $100.8 \pm 15.4$ & $121.9 \pm 14.5^{*}$ \\
\hline Group R & $84.2 \pm 14.3$ & $78.2 \pm 14.3^{*}$ & $99.0 \pm 18.6^{*}$ & $96.3 \pm 19.25$ & $96.6 \pm 19.5$ & $113.7 \pm 16.3^{*}$ \\
\hline Group C & $88.9 \pm 13.0$ & $75.3 \pm 9.2 *$ & $99.5 \pm 15.4^{*}$ & $94.8 \pm 14.1$ & $94.2 \pm 12.4$ & $116.1 \pm 12.7^{*}$ \\
\hline
\end{tabular}

Data are given as means \pm SD. MAP: mean arterial blood pressure, HR: heart rate, baseline; upon arrival in the operating room. Group S: Sevoflurane group, Group R: Remifentanil group, Group C: Sevoflurane and remifentanil combination group. $* \mathrm{P}<0.05$ compared with baseline value within the group. 
pared with baseline $(\mathrm{P}<0.05)$. In addition, MAP was significantly decreased all the three groups before tracheal intubation as compared with baseline $(\mathrm{P}<0.05)$. Furthermore, there were no significant differences in time-dependent changes in the MAP and HR between the three groups $(\mathrm{P}<0.05)$.

\section{Discussion}

Our results showed that the incidence of withdrawal movements on rocuronium injection was decreased during the induction of anesthesia with sevoflurane inhalation to an equivalent extent to intravenous remifentanil. Moreover, our results also showed that the degree of the effect of sevoflurane inhalation against withdrwal movements on rocuronium injection was significantly higher when combined with intravenous remifentanil as compared with the single use of sevoflurane inhalation or intravenous remifentanil.

To date, several hypotheses have been proposed to explain the pathophysiology of pain on rocuronium injection. Still, however, little is known about it. It has been simply speculated that the low $\mathrm{pH}$ of rocuronium $(\mathrm{pH}=4)$ might be responsible for the occurrence of pain on rocuronium injection when it is supplied as an isotonic solution [12]. But this is not plausible because patients commonly present with no pain when receiving injections of normal saline buffered to $\mathrm{pH} 4$ [1]. On the other hand, it has also been speculated that pain on rocuronium injection occurs as a result of the release of local mediators, such as kinins, stimulating the venous nociceptors [13] as well as the allogenic effect of aminosteroidal neuromuscular blocking drugs, possibly activating C-nociceptors [14].

According to a recent study, there was a time-dependent decrease in the incidence of withdrawal movements on rocuronium injection during the induction of anesthesia with sevoflurane inhalation and inhalation of sevoflurane (required endtidal concentration of $5.5 \pm 0.7 \mathrm{vol} \%$ ) with $67 \%$ of nitrous oxide completely prevented withdrawal movement even in the absence of pre-medication. This study also showed that it took 1.7 and 2.3 minutes to abolish withdrawal movements on rocuronium injection during the induction of anesthesia with sevoflurane inhalation in 50 and $95 \%$ of children, respectively [8]. It has been shown that remifentanil pre-treatment at a dose of $1.0 \mathrm{or} 0.5 \mu \mathrm{g} /$ $\mathrm{kg}$ is effective in preventing the occurrence of withdrawal movements on rocuronium injection in children [7,9].

Our results showed that the overall incidence of withdrawal movements on rocuronium injection was $53 \%(16 / 30)$ in the Group S, 57\% (17/30) in the Group R and 17\% (5/30) in the Group C. These results are consistent with previous reports that it was $53 \%$ in children who were pre-treated using remifentanil at a dose of $0.5 \mu \mathrm{g} / \mathrm{kg}$ [9]. For the current study, we determined the dose of remifentanil and the end-tidal concentration of sevoflurane based on these reports. Thus, we found that there was a decrease in the incidence of withdrawal movements on rocuronium injection and there was no significant difference in the degree of decrease between children receiving sevoflurane inhalation at an end-tidal concentration of 2 vol\% and those doing intravenous remifentanil at a dose of $0.5 \mu \mathrm{g} / \mathrm{kg}$.

We assume that sevoflurane inhalation combined by pretreatment with intravenous remifentanil caused a higher level of anesthesia, thus effectively increasing the pain threshold at the time of the rocuronium injection and decreasing the incidence of withdrawal movements on rocuronium injection. Our results showed that the incidence of withdrawal movements on rocuronium injection was significantly lower in the Group $\mathrm{C}$ as compared with the Group S and Group R $(\mathrm{P}<0.05)$. These results indicate that sevoflurane inhalation enhances the analgesic efficacy of intravenous remifentanil. But this deserves further studies. According to a review of literatures, our study is the first to examine the pre-treatment efficacy of sevoflurane inhalation alone or in combination with intravenous remifentanil in reducing pain on rocuronium injection in children. Moreover, the combination of sevoflurane inhalation and pre-treatment with intravenous remifentail was more effective in reducing the incidence of pain upon the injection of rocuronium than either treatment alone.

In the current study, there were significant differences in time-dependent changes in the HR and MAP between at baseline and after tracheal intubation and those in the MAP between at baseline and before tracheal intubation in all the three groups. But time-dependent changes in the HR and MAP reached no clinical significance. In our series, there were no complications, such as desaturation, apnea or chest wall rigidity during the induction of anesthesia.

In the current study, we performed injections slowly for more than 30 seconds, thus attempting to minimize the occurrence of adverse effects of opioids, including hypotension, bradycardia and muscular rigidity. It has been reported that these adverse effects occur at a higher incidence after intravenous remifentanil as compared with other opioids [9]. In our series, there were no notable complications due to intravenous injections of remifentanil. There were some cases of coughing, which was not of great severity. All the patients were successfully anesthetized without further problems.

There are two limitations of the current study as shown below:

(1) We failed to use a high-dose of intravenous remifentanil that may cause a greater decrease in the incidence of withdrawal movements on rocuronium injection. A high-dose of intravenous remifentanil would be of clinical benefit unless there are increased complications.

(2) We failed to evaluate the incidence of withdrawal move- 
ments on rocuronium injection at baseline in a casecontrol setting because we are aware that it is unethical to withhold prophylactic interventions in children who are at increased risks of developing withdrawal movements on rocuronium injection. This deserves further studies.

In conclusion, our results indicate not only that there was no significant difference in the degree of the effect in lowering the incidence of withdrawal movements on rocuronium injection between sevoflurane inhalation and intravenous remifentanil but also that it was significantly higher when combined with intravenous remifentanil as compared with the single use of sevoflurane inhalation or intravenous remifentanil.

\section{References}

1. Borgeat A, Kwiatkowski D. Spontaneous movements associated with rocuronium: is pain on injection the cause? Br J Anaesth 1997; 79: $382-3$.

2. Liou JT, Hsu JC, Liu FC, Ching-Wah Sum D, Lui PW. Pretreatment with small-dose ketamine reduces withdrawal movements associated with injection of rocuronium in pediatric patients. Anesth Analg 2003; 97: 1294-7.

3. Kim JY, Kim JY, Kim YB, Kwak HJ. Pretreatment with remifentanil to prevent withdrawal after rocuronium in children. Br J Anaesth 2007; 98: 120-3.

4. Lui JT, Huang SJ, Yang CY, Hsu JC, Lui PW. Rocuronium-induced generalized spontaneous movements cause pulmonary aspiration. Chang Gung Med J 2002; 25: 617-20.

5. Shin YH, Kim CS, Lee JH, Sim WS, Ko JS, Cho HS, et al. Dilution and slow injection reduces the incidence of rocuronium-induced withdrawal movements in children. Korean J Anesthesiol 2011; 61: 465-9.

6. Cheong KF, Wong WH. Pain on injection of rocuronium: influence of two doses of lidocaine pretreatment. Br J Anaesth 2000; 84: 106-7.

7. Oh AY, Seo KS, Goo EK, Park YO, Kim SJ, Kim JH. Prevention of withdrawal movement associated with injection of rocuronium in children: comparison of remifentanil, alfentanil and fentanyl. Acta Anaesthesiol Scand 2007; 51: 1190-3.

8. Park SH, Oh AY, Goo EK, Nahm FS, Min SW, Hwang JW, et al. A short period of inhalation induction with sevoflurane prevents rocuronium-induced withdrawal in children. Acta Anaesthesiol Scand 2011; 55: 87-91.

9. Kim JY, Kwak HJ, Kim JY, Park KS, Song JS. Prevention of rocuronium-induced withdrawal movement in children: a comparison of remifentanil with alfentanil. Paediatr Anaesth 2008; 18: 245-50.

10. Scott LJ, Perry CM. Remifentanil: a review of its use during the induction and maintenance of general anaesthesia. Drugs 2005; 65: 1793-823.

11. Shevchenko Y, Jocson JC, McRae VA, Stayer SA, Schwartz RE, Rehman M, et al. The use of lidocaine for preventing the withdrawal associated with the injection of rocuronium in children and adolescents. Anesth Analg 1999; 88: 746-8.

12. Klement W, Arndt JO. Pain on i.v. injection of some anaesthetic agents is evoked by the unphysiological osmolality or pH of their formulations. Br J Anaesth 1991; 66: 189-95.

13. Kindgen-Milles D, Klement W, Arndt JO. The nociceptive systems of skin, paravascular tissue and hand veins of humans and their sensitivity to bradykinin. Neurosci Lett 1994; 181: 39-42.

14. Blunk JA, Seifert F, Schmelz M, Reeh PW, Koppert W. Injection pain of rocuronium and vecuronium is evoked by direct activation of nociceptive nerve endings. Eur J Anaesthesiol 2003; 20: 245-53. 